\title{
Laboratory studies on the oviposition stimuli of Culicoides stellifer (Diptera: Ceratopogonidae), a suspected vector of Orbiviruses in the United States
}

\author{
Dinesh Erram* and Nathan Burkett-Cadena
}

\begin{abstract}
Background: Biting midges of the genus Culicoides (Diptera: Ceratopogonidae) exert a significant impact on animal agriculture worldwide because they transmit bluetongue virus (BTV) and epizootic hemorrhagic disease virus (EHDV) to ruminants. Without effective vaccines, BTV/EHDV vector management strategies are needed, particularly in commercial white-tailed deer (WTD) facilities. However, detailed information on the ecology of midge immatures in/around cervid operations is currently lacking. Towards filling this knowledge gap, we conducted two-choice oviposition experiments with field-collected Culicoides stellifer Coquillett (a suspected vector of BTV/EHDV in the USA) under laboratory conditions to examine which natural source from the larval habitat is relatively more attractive for midge oviposition.
\end{abstract}

Methods: Field-collected C. stellifer females (CDC-UV light traps) were given a blood meal from live chicken and examined for their oviposition preferences for individual (or mixed) potential larval habitat oviposition stimuli in two-choice bioassays. Substrates included mud from C. stellifer habitat, mud from allopatric site, vegetation (Sphagnum spp. mosses), field water, WTD manure and de-ionized water (control).

Results: The majority of midges (91\%) oviposited in only one dish, with few females (9\%) ovipositing in both the dishes. Gravid females demonstrated an overall oviposition preference for substrates with mud and vegetation from the larval habitat, depositing a significantly higher proportion of eggs on mud (52.3\%) and vegetation (81.8\%) than on controls $(\leq 18.2 \%)(P \leq 0.0320)$. Moreover, greater number of eggs per female were deposited on mud (29.5-40.7 depending on trial) and vegetation (38.2) than on controls ( $\leq 5.8)$. WTD manure, field water and mud from allopatric site were not found to be more attractive than controls for oviposition. Combining individual substrates (mud + WTD manure; mud + moss + WTD manure + field water) did not elicit greater oviposition responses than mud or moss alone.

Conclusions: Management strategies to discourage C. stellifer oviposition in/around commercial cervid facilities should likely focus on mud and/or vegetation, rather than WTD manure. However, further studies are needed to examine whether the spatial distributions of $C$. stellifer and Sphagnum spp. moss are correlated, and to determine whether targeting vegetation in/around cervid facilities can contribute to reductions in local midge densities.

Keywords: Culicoides stellifer, Biting midges, Oviposition, Hemorrhagic disease, Ruminants

\footnotetext{
* Correspondence: derram@ufl.edu

Florida Medical Entomology Laboratory, University of Florida, IFAS, 200 9th

St. SE, Vero Beach, FL 32962, USA
}

(c) The Author(s). 2018 Open Access This article is distributed under the terms of the Creative Commons Attribution 4.0 International License (http://creativecommons.org/licenses/by/4.0/), which permits unrestricted use, distribution, and reproduction in any medium, provided you give appropriate credit to the original author(s) and the source, provide a link to the Creative Commons license, and indicate if changes were made. The Creative Commons Public Domain Dedication waiver (http://creativecommons.org/publicdomain/zero/1.0/) applies to the data made available in this article, unless otherwise stated. 


\section{Background}

Biting midges in the genus Culicoides (Diptera: Ceratopogonidae) are of significant medical and veterinary importance worldwide because the bites of females can result in major annoyance, pathogen transmission, and/ or hypersensitivity reaction in susceptible hosts [1, 2]. Among the several pathogen classes that Culicoides species transmit, two arboviruses affecting ruminants, bluetongue virus (BTV) and epizootic hemorrhagic disease virus (EHDV) (Genus Orbivirus, Family Reoviridae), cause significant morbidity, mortality, and economic losses in animal agriculture worldwide [3]. Although these viruses affect a variety of domestic and wild ruminants, BTV affects primarily sheep and cattle, while EHDV affects mainly white-tailed deer (WTD) (Odocoileus virginianus Zimmermann) and also cattle [4]. Unfortunately, no effective midge control strategies currently exist, primarily because many of the fundamental biological aspects of the Culicoides species associated with BTV/EHDV transmission are poorly understood $[1,2]$.

Currently, the only confirmed vectors of BTV/EHDV in North America are Culicoides sonorensis Wirth \& Jones (BTV and EHDV), and Culicoides insignis Lutz (BTV) [3, 5-7]. In the USA, C. sonorensis has been known to occur primarily through the western states and scattered/rare through the east [2, 8-10]. However, recent findings of this species in southern Ontario, Canada suggest that $C$. sonorensis may have undergone a major range expansion towards the northeast [11], or is poorly documented in some parts of its range. The distribution of $C$. insignis in the USA is primarily limited to Florida and neighboring states; however, recent reports suggest a northward range expansion of this species as well [10].

Entomological investigations during BTV/EHDV outbreaks in several southeastern states (Mississippi, Alabama, Georgia and North Carolina) have found that the confirmed vectors $C$. sonorensis and $C$. insignis were either absent or only present in very low numbers in light trap collections or animal aspirations [8, 9, 12-14]. In addition, the distributions of $C$. sonorensis and $C$. insignis overlap only partially with that of EHDV in the USA [15]. Moreover, field associations between these confirmed vectors and BTV/EHDV outbreaks in WTD have been rare, with only one report from Kentucky documenting $C$. sonorensis to be the predominant midge species during disease outbreaks [6]. The lack of temporal and spatial association of BTV/EHDV outbreaks with $C$. sonorensis or $C$. insignis abundance in several states suggests that other Culicoides species are likely involved in virus transmission, particularly in the southeastern USA. Two biting midge species that have been suggested as putative vectors of BTV/EHDV in these states are Culicoides debilipalpis Lutz and Culicoides stellifer Coquillett.

Culicoides stellifer is known to occur throughout most of the USA (between latitudes approximately $49^{\circ} \mathrm{N}$ to $25^{\circ} \mathrm{N}$ ) with its distribution in North America ranging from Montana and Nova Scotia in the North to California and Florida in the south [16]. This midge species is one of the most common species found in the eastern USA, and its immature stages have been suggested to occur in a variety of organically enriched mud substrates [16]. However, other than general descriptive reports of where the larvae were previously found, studies characterizing the larval habitat of $C$. stellifer are lacking, which has significant implications limiting the design and implementation of management/survey strategies against this putative vector species. Much of our knowledge on the larval habitat characteristics of BTV/EHDV vectors in North America arises from studies on $C$. sonorensis, the larvae of which are known to occur mainly in animal-waste enhanced muds [17-23]. Comparatively, little detailed information is available regarding the habitat characteristics of other suspected/ potential vector Culicoides species associated with BTV/ EHDV transmission in North America. Moreover, oviposition in Culicoides species worldwide has received very little attention to date [18, 24-27], with the oviposition of North American Culicoides species being virtually unexplored [25, 27]. Therefore, many of the parameters involved in the oviposition site selection of Culicoides species pertinent to animal virus transmission in North America and other parts of the world are unknown. In mosquitoes and other dipterans, many physical and/or chemical cues have been shown to influence insect oviposition [28-32]. Similar studies on Culicoides species are lacking and generating such fundamental information may provide clues towards colonization of target species and eventual establishment of control strategies by targeting gravid females and/or immature stages [33, 34]. Thus, with a long-term goal of developing midge management strategies, particularly in commercial cervid facilities, we conducted two-choice oviposition experiments on field-collected C. stellifer midges under laboratory conditions to examine which natural substrates from the larval habitat (mud, vegetation, standing water, or host animal manure) are relatively more attractive for midge oviposition.

\section{Methods}

\section{Live biting midge collection}

Live biting midges were collected from a private game ranch in Quincy, Gadsden County, FL, USA, (GPS coordinates: $\left.30^{\circ} 28^{\prime} 35.2^{\prime \prime} \mathrm{N}, 84^{\circ} 38^{\prime} 54.9^{\prime \prime} \mathrm{W}\right)$ using CDC miniature UV light traps connected to live midge collection chambers. The CDC light traps (model \#2836BQ, 
BioQuip products, Rancho Dominguez, CA, USA) utilized blacklight LED arrays as the sole attractant (catalog \#2790V390, BioQuip products, Rancho Dominguez, CA, USA). The live midge collection chamber consisted of 1 . 9 or 3.81 plastic canisters (Mainstays, Walmart, Vero Beach, FL, USA) with a circular hole $(10 \mathrm{~cm}$ diameter) cut through the lid allowing the passage and connection of a standard drawstring sleeve (Fig. 1a). An $8 \mathrm{~cm}$ diameter hole (or pair of holes) were drilled through the canister walls and sealed with a fine mesh to allow the escape of air flowing from the fan of the light trap blowing into the canister but also prevent insect escape. To separate live Culicoides from the substantial by-catch (Fig. 1b), the trap collection chamber was returned to the laboratory and connected to a sorting chamber (Fig. 1c). The sorting chamber consisted of a similarly sized container connected to the collection chamber at their lids (using duct tape) and separated by a screen (20mesh size) and a funnel (diameter of the narrow end $\sim 2$. $0 \mathrm{~cm}$ ). The collection chamber was then wrapped with a black towel to create a darker environment so that insects displaying positive phototactic behavior in the collection chamber would voluntarily migrate to the brighter (sorting) chamber. The sorting chamber was also provided with cotton pads moistened with $10 \%$ sucrose solution as additional incentive. The mesh screen between the two chambers excludes the passage of larger insects. Culicoides females sorted in this manner were transferred to $500 \mathrm{ml}$ non-waxed cardboard cups sealed with no-see-um netting on top using a mouth aspirator. Culicoides stellifer females were sorted from other
Culicoides spp. using morphological characters [16] of anesthetized midges under a stereoscopic microscope (Nikon SMZ 745). Biting midges were anesthetized using one drop of triethylamine (TEA) (Fisher Scientific 04884-100, Atlanta, GA, USA) diluted 10× in ethanol pipetted onto a piece of cotton that was placed on the mesh of paper cup and covered with a Petri dish [35]. TEA exposure periods were 2-3 min or until all midges stopped moving. Culicoides stellifer females were transferred to paper cups as above and provided with cotton pads moistened with $10 \%$ sucrose solution, changed daily, until use.

\section{Oviposition substrates}

Types of oviposition substrates selected were based on personal observations and published reports [23, 26, 27]. Field water was collected into $50 \mathrm{ml}$ conical tubes by dipping the tube into shaded puddles in lowland hardwood forests in Quincy, FL, USA, at the approximate location of C. stellifer light trap collections. Year-round sampling from this location indicated that C. stellifer constituted > $75 \%$ of light trap and emergence trap collections (data not shown). White-tailed deer manure ( $<6 \mathrm{~h}$ old $)[23,27]$ was collected from the floor of breeding pens from a commercial WTD facility in Okeechobee, FL, USA. Diet of the deer included a locally prepared commercial feed of $16 \%$ deer pellets (Odolicious 200, Walpole Feed and Supply Co., Okeechobee, FL, USA), corn treats, peanut hay, and browse consisting of wild grape vines, oak leaves and grass. No animals were treated with insecticides or antibiotics for at least one month prior to the days of manure

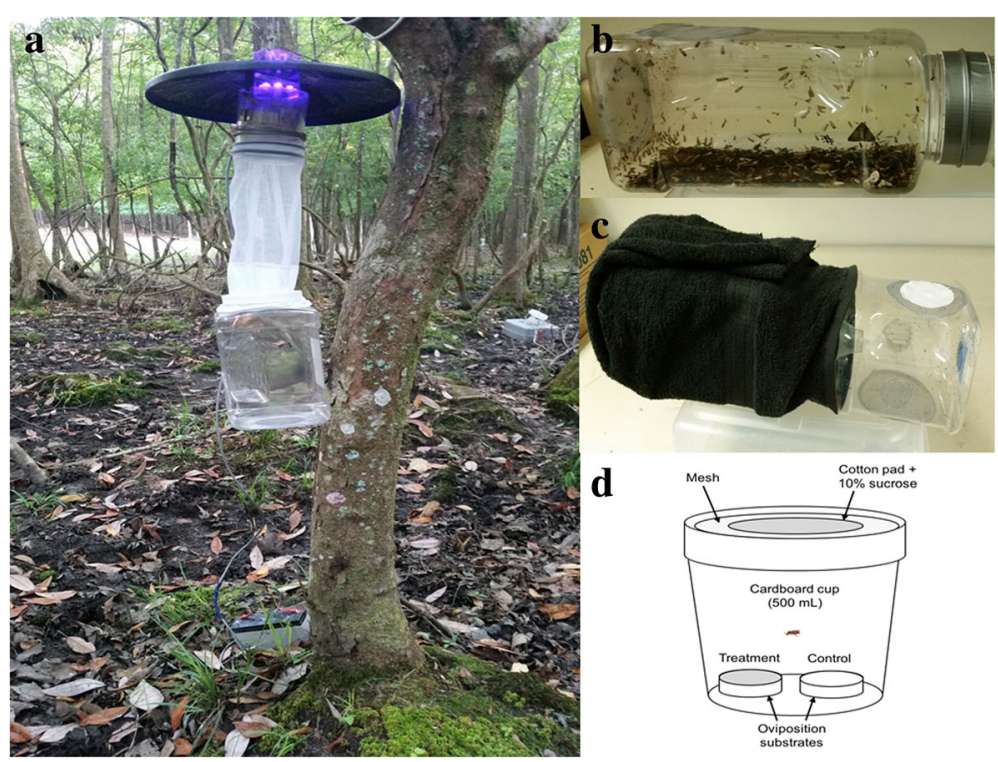

Fig. 1 CDC miniature light traps set up overnight on the larval habitat of C. stellifer at a commercial deer farm in Quincy, FL, USA, to capture live midges (a). Trap collections returned to laboratory the next morning (b). The trap collection chamber connected to a sorting chamber and covered with a black cloth for Culicoides species to move into the sorting chamber (c). Set-up of the two-choice oviposition bioassays (d) 
collection. Moss (Sphagnum spp.) [26] was sampled from the shaded forest floor in Quincy, FL, USA, in the vicinity of verified larval development sites using a trowel. 'Sympatric mud' was sampled from the same lowland forest location as field water and moss, also using a trowel. 'Allopatric mud' was sampled from MacArthur Agroecology Research Center, Lake Placid, Highlands County,

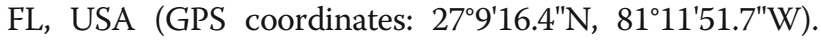
Sampling at this location indicated that $C$. stellifer was a very minor constituent of the biting midge community (< $1 \%$ of Culicoides in light traps and no C. stellifer emerged from this mud but mainly C. insignis) (data not shown).

Oviposition substrates were presented to blood-fed midges in plastic Petri dishes $(35 \times 10 \mathrm{~mm})$ with $1 \mathrm{~g}$ of the chosen substrate and $1.5 \mathrm{ml}$ of deionized water (DI control). Mud, moss or WTD manure (each homogenized individually using mortar and pestle) were placed in the dish and covered with cotton and filter paper. Field water substrate consisted of cotton and filter paper moistened with $1.5 \mathrm{ml}$ of field water. Control substrates consisted of cotton and filter paper. Moisture levels across control and treatment dishes were kept constant by adding $1.5 \mathrm{ml}$ deionized water to each dish. The 'combined' substrates were prepared by mixing equal parts (by weight) of sympatric mud, moss, and WTD manure and $1.5 \mathrm{ml}$ of field water. The substrates with sympatric mud + WTD manure were prepared by mixing 3 parts mud and 1 part manure. Each Petri dish was hot-glued to the bottom of the paper cup to minimize Petri dish movements within the cup that may crush females during handling.

\section{Oviposition assays}

Culicoides stellifer females were fed upon the blood of a live, restrained chicken after a starvation period of 6-24 h. Starved females were first transferred to $50 \mathrm{ml}$ conical tubes (in groups of 20-30), and the conical tubes, fitted with fine mesh screen caps, were pressed downwards against the breast of the chicken for 30-45 min. Subsequently, blood-fed females were sorted from unfed females (partially blood-fed and fully-engorged females not discriminated) using TEA anesthesia as described above and placed in separate paper cups for $48 \mathrm{~h}$ to allow egg development. Cotton pads moistened with $10 \%$ sucrose solution were replaced daily. Thereafter, individual females were transferred to $500 \mathrm{ml}$ paper cups in which two oviposition substrates were previously placed, and the females were monitored and allowed to oviposit for 14 days (Fig. 1d). At the end of the two weeks or following midge death, eggs on the oviposition substrates were counted and midges were dissected to determine the number of retained eggs, if any. Cotton pads moistened with $10 \%$ sucrose solution given to the females were replaced daily.

Altogether eight different two-choice experiments were conducted testing the relative importance of various environmental substrates on midge oviposition (Table 1). Four experiments tested a single substrate (sympatric mud or moss or field water or WTD manure) $v s$ a control (DI water); one experiment tested combined substrates (mud + moss + WTD manure + field water) $v s$ a DI water control; two experiments tested substrate against other substrates (sympatric mud + WTD manure vs sympatric mud control, and sympatric mud vs allopatric mud); and one experiment tested control vs control (DI water). Each experiment had at least 5 replicates using a single midge per replicate and was repeated at least two times (Table 1). Environmental conditions in the walk-in incubator where the experiments were conducted were $26 \pm 1{ }^{\circ} \mathrm{C}, 60-80 \%$ RH and 16:8 (L:D) h photoperiod cycle.

\section{Statistical analysis}

Only gravid females were considered for statistical analyses and non-gravid females were excluded from the analyses. Variation in the gravid levels (number of eggs developed within individual midges) of field-collected

Table 1 Summary of the oviposition experiments on C. stellifer under different two-choice conditions

\begin{tabular}{|c|c|c|c|c|c|c|c|}
\hline Experiment & Treatment vs control & $\begin{array}{l}\text { Trials }^{a} \text { (replicates } \\
\text { within each trial) }\end{array}$ & $\begin{array}{l}\text { Blood-fed } \\
\text { females }(n)\end{array}$ & $\begin{array}{l}\text { Gravid } \\
\text { females }(n)\end{array}$ & $\begin{array}{l}\text { Oviposited } \\
\text { females }(n)\end{array}$ & $\begin{array}{l}\text { Odds ratio } \\
(95 \% \mathrm{Cl})\end{array}$ & $P$-value \\
\hline 1 & DI control vs DI control & $2(6)$ & 12 & 10 & 3 & $1.0(0.2-4.1)$ & 0.9890 \\
\hline 2 & Field water vs DI control & $2(6)$ & 12 & 9 & 2 & 0 & 1.0000 \\
\hline 3 & Sympatric mud vs DI control & $2(6)$ & 12 & 11 & 6 & $4.4(1.7-11.8)$ & 0.0042 \\
\hline 4 & WTD manure vs DI control & $2(7)$ & 14 & 10 & 4 & $0.4(0.1-2.0)$ & 0.2500 \\
\hline 5 & Moss vs DI control & $2(8-9)$ & 17 & 11 & 11 & $9.3(1.5-59.0)$ & 0.0320 \\
\hline 6 & Combined substrates vs DI control & $3(5-6)$ & 17 & 13 & 5 & $6.6(2.3-19.2)$ & 0.0014 \\
\hline 7 & Sympatric mud + WTD manure vs Sympatric mud & $5(5-6)$ & 27 & 21 & 7 & $0.67(0.2-2.6)$ & 0.5700 \\
\hline 8 & Sympatric mud vs Allopatric mud & $2(6-8)$ & 14 & 13 & 6 & $6.2(2.2-19.2)$ & 0.0007 \\
\hline
\end{tabular}

${ }^{\mathrm{a}}$ Trials within an experiment were not significantly different $(P>0.05)$

bSignificant $P$-values (odds ratio) shown in bold $(P<0.05)$

Abbreviations: WTD white-tailed deer, $\mathrm{Cl}$ confidence interval 
females collected across the experiments was analyzed using generalized linear models (GLM) under a negative binomial distribution with log link function. The proportion of egg batch deposited by individual females across experiments was analyzed using GLM with binomial distribution of the residuals. The preferences of females in the two choice experiments (treatment $v s$ control) were analyzed using generalized estimation equations (GEE) to estimate the odds of a female choosing the treatment substrates over controls, in addition to examining differences between trials. The GEE models were fitted with a binomial distribution incorporating a logit link function taking into consideration the proportion of eggs retained by females that deposited eggs. As each midge was given two choices for oviposition (treatment $v s$ control), data obtained from the two substrates were related; therefore, each midge within a given trial was considered a cluster and the models were fitted assuming an exchangeable working correlation structure [36, 37]. Differences in the proportion of females ovipositing on one or both the dishes was analyzed using a t-test. Statistical analyses were conducted using $\mathrm{R}$ statistical software version 3.303 [38] with the packages MASS [39], car [40] and geepack [41] or SAS version 9.4 (PROC TTEST) [42].

\section{Results}

Overall, the proportion of females that developed an egg batch following a blood meal (of the total females collected) was high and ranged from 65\% (11/17 females during moss $v s$ DI control trials) to $92 \%$ (11/12 females during sympatric mud $v s$ DI control trials) across the study (Table 1). The average size of egg batch was $35.9 \pm$ 2.5 (mean \pm SE) eggs per female; however, the number of eggs developed within individual females (gravid levels) varied significantly, from a low of just 4 eggs, to a high of 119 eggs $\left(\operatorname{LR} X^{2} 7,97=30.5, P<0.0001\right)$. Moreover, not all gravid females deposited eggs; the proportion of gravid females that successfully deposited eggs varied greatly from 22\% (2/9 gravid females during field water vs DI control trials) to $100 \%$ (11/11 gravid females during moss vs DI control trials) (Table 1). Furthermore, the proportion of egg batch deposited by individual females (treatment + control) varied significantly across experiments from 58\% (sympatric mud vs DI control trials) to $100 \%$ (moss $v s$ DI control trials) $\left(\operatorname{LR} \chi^{2}{ }_{7,97}=916\right.$, $P<0.0001$ ) (Fig. 2a, b).

During sympatric mud $v s$ DI control trials, midges deposited a higher proportion of eggs on mud substrates (52.3 \pm $15.4 \%)($ mean \pm SE) than on DI controls $(5.6 \pm 4.2 \%)$. The odds of a female choosing the mud substrate for oviposition was 4.4 times higher than DI controls (odds ratio $[\mathrm{OR}]=4$. 4; 95\% CI: $1.7-11.8 ; P=0.0042$ ), with no significant difference between the two trials conducted (Wald $\chi^{2}{ }_{1,10}=0.02$, $P=0.8890$ ) (Fig. 2a, b, Table 1). During moss $v s$ DI control trials, midges deposited a higher proportion of eggs on moss substrates $(81.8 \pm 12.2 \%)$ than on DI controls $(18.2 \pm$

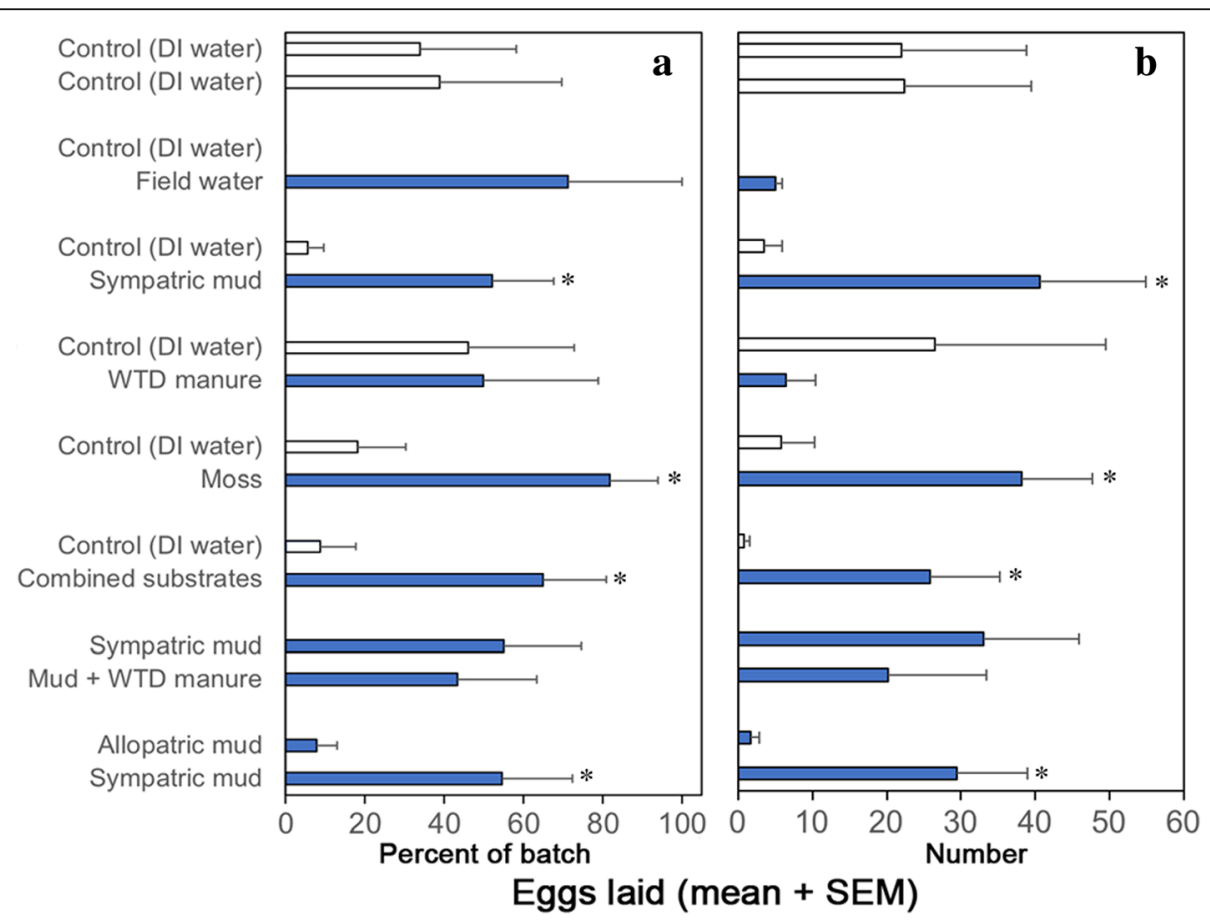

Fig. 2 Oviposition preferences of C. stellifer under different two-choice conditions. The percentage of egg batch deposited (a), and the number of eggs deposited (b), by individual females across all experiments. Asterisk indicates that midge preference for treatment substrates over controls within each experiment (odds ratio) was significant $(P<0.05)$. White bars indicate control (DI water) 
$12.2 \%)$. The odds of a female choosing the moss substrate was 9.3 times higher than DI controls (OR $=9.3 ; 95 \%$ CI: 1 . 5-59; $P=0.0320$ ) and the two trials conducted were not significantly different from each other (Wald $\chi_{1,10}^{2}=0.30$, $P=0.5860$ ). During field water $v s$ DI control trials, the proportion of eggs deposited on field water treatment (71.4 $\pm 28.6 \%)$ was much higher than DI controls $(0.0 \pm 0.0)$; however, the odds of a female choosing the field water substrate for oviposition over DI controls were very low $(\mathrm{OR}=0.0$; 95\% CI: $0.0-0.0 ; P=1.0000)$, with no significant difference between the two trials conducted (Wald $\chi_{1,8}^{2}=$ $0.08, P=0.7700$ ). During WTD manure $v s$ DI control trials, the proportion of eggs deposited on WTD manure $(50 \pm 28.9 \%)$ was slightly higher than on DI controls $(46.2$ \pm 26.8 ), but the odds of a female choosing WTD manure over DI controls were low $(\mathrm{OR}=0.4 ; 95 \%$ CI: $0.1-2 ; P=0$. $2500)$ and the two trials conducted were not significantly different from each other (Wald $\chi_{1,9}^{2}=0.09, P=0.7400$ ) (Fig. 2a, b, Table 1).

During combined substrates vs DI control trials, midges deposited a higher proportion of eggs on combined substrates $(65 \pm 15.9 \%)$ than on DI controls $(8.9 \pm$ $8.9 \%$ ), with the odds of a female choosing the combined substrates being 6.6 times higher than DI control substrates $(\mathrm{OR}=6.6 ; 95 \% \mathrm{CI}: 2.3-19.2 ; P=0.0014)$; the three trials conducted were not significantly different from each other (Wald $X_{2,12}^{2}=0.03, P=0.8620$ ). During sympatric mud + manure vs sympatric mud control trials, the proportion of eggs deposited on the mud + manure substrates $(43.4 \pm 20 \%)$ was slightly lower than mud controls $(55.1 \pm 19.5 \%)$, and the odds of a female choosing the mud + manure substrates for oviposition over mud control substrates were low (OR = 0.67; 95\% CI: $0.2-2.6 ; \quad P=0.5700$ ); the five trials conducted were not significantly different from each other (Wald $\chi_{4,20}^{2}=1.29, P=0.2560$ ). During sympatric mud $v s$ allopatric mud trials, midges deposited a higher proportion of eggs on sympatric mud substrates (54.7 \pm $17.7 \%)$ than on allopatric mud controls $(8 \pm 5.2 \%)$. The odds of a female choosing sympatric mud was 6.2 times higher than allopatric mud (OR $=6.2$; 95\% CI: 2.2-19.2; $P=0.0007)$ and the two trials were not significantly different from each other (Wald $X_{1,12}^{2}=0.17, P=0$. 6810). During the double control trials (DI control vs DI control), the odds of a female choosing one substrate over the other was low $(\mathrm{OR}=1 ; 95 \%$ CI: $0.2-4.1 ; P=0$. 9890) (mean proportion of eggs deposited on either substrate $\leq 38.9 \%$ ) with no significant difference between the two trials conducted (Wald $X_{1,9}^{2}=0.22, P$ $=0.6400$ ) (Fig. 2a, b, Table 1).

A significantly higher proportion of females (91\%; 40/ 44) across the experiments deposited all their eggs on a single dish, compared to females that oviposited in both assay dishes $(t=8.43, d f=14, P<0.001)$ (Fig. 3).

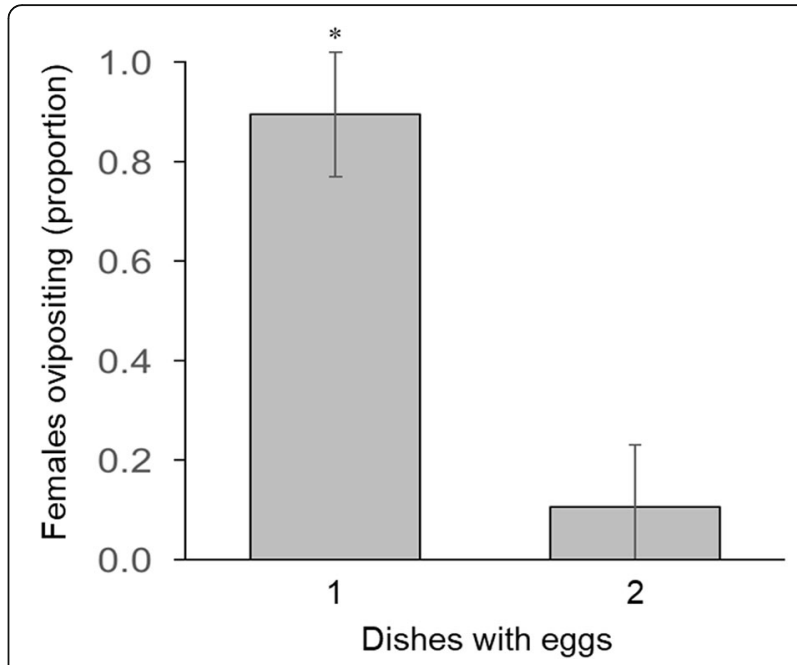

Fig. 3 Proportion of females that oviposited on one or both dishes across all experiments. Asterisk indicates significant differences as determined by $t$-test $(P<0.05)$

Throughout the study, only four females deposited eggs in both substrate dishes, each from a different experiment. In two of these, the female laid most of the eggs in one dish (53 eggs in sympatric mud dish vs 6 in DI control dish [Additional file 1: Table S3], 75 eggs in mud dish vs 3 in mud + WTD manure dish [Table S7]). In the combined substrates $v s$ DI control experiment one female laid nearly equivalent numbers of eggs in the two dishes (5 and 4) (Table S6). In DI control vs DI control experiment one female laid 11 and 55 eggs in the two control dishes, respectively (Additional file 1: Table S1). All other females $(n=40)$ laid all eggs in just one of the assay dishes (Fig. 3; Additional file 1: Table S1-S8).

\section{Discussion}

Overall, our results suggest that mud and vegetation from the larval habitat provide stronger oviposition cues to $C$. stellifer than field water or host animal manure. However, whether these cues are olfactory or tactile in nature is currently unknown and remains to be examined in further studies. In general, midges deposited a distinctly higher proportion of eggs on substrates with mud or vegetation than on DI controls, but the proportion of eggs deposited on field water or WTD manure substrates was not much different to those deposited on DI controls. We further hypothesized that the individual substrates chosen from the larval habitat may have a synergistic effect on midge oviposition. However, although a higher proportion of eggs were deposited on the combined substrates over DI controls, the total proportion of eggs (treatment + control) deposited during these trials (combined vs DI controls) was noticeably lower (73.9\%) than those deposited during experiments using moss or WTD manure alone $(\geq 96.2 \%$ ) ( $v s$ DI 
controls) (Fig. 2a, b). This suggests that the effect of combined treatment on midge oviposition was subadditive rather than synergistic, which is possibly due to an inhibitory effect of one or more of the individual sources on C. stellifer oviposition. Previously, sand flies (Lutzomyia longipalpis Lutz \& Neiva and Phlebotomus papatasi Scopoli) deposited significantly more number of eggs on substrates containing frass from laboratory colonies; however, the effect of substrates containing a combination of frass and conspecific eggs was found to be sub-additive [43].

Mud from the larval habitat (irrespective of the presence of WTD manure) appears to play a strong role in positively influencing the oviposition of $C$. stellifer. This is evident from the mud + WTD manure vs mud control experiments where the mean proportion of eggs deposited on either substrate was not distinctly different. However, the mean proportion of eggs deposited during mud vs DI control trials was distinctly higher on mud substrates over DI controls. Moreover, during subsequent experiments, $C$. stellifer females deposited a higher proportion of eggs on mud from a sympatric site (larval habitat) over mud from an allopatric site. Currently, the biotic/abiotic factors in the mud that play key roles in influencing midge oviposition are not known; also, unknown are the reasons for the preference of C. stellifer gravid females for the larval habitat mud (sympatric mud) over allopatric mud. However, possible hypotheses include: (i) presence of residues from dead/decaying organic matter such as leaf litter, wooden debris, or manure from certain animals that may be more attractive than others [18, 22, 44-46]; (ii) differences in chemical properties that may play a role in the spatial ecology of midges; for example salinity has been shown to influence oviposition in C. sonorensis [25, 47-49]; (iii) variation in diversity of the microbial communities in different muds with certain microbial taxa possibly being more attractive than others [50-53]; (iv) chemical cues from conspecifics, competitors or predators that may attract/repel gravid females [28, 54-57]; or (v) chemical cues from certain types of vegetation that may influence midge oviposition [58-60]; (vi) site fidelity [61-63]; or (vii) some oviposition cues originating from the larval habitat may be species specific [64]. However, further studies will be needed to test these hypotheses in Culicoides species.

Commercial cervid farming is a growing industry in the United States with an estimated total economic impact of around $\$ 2.3$ billion annually [65]. As such, orbiviruses such as BTV/EHDV transmitted by Culicoides species pose a major threat to cervid farming industry as they cause hemorrhagic disease in WTD that can result in high mortality in deer populations and significant economic losses to deer farmers [4]. While the immature stages of C. sonorensis (a confirmed vector of BTV and EHDV in
North America) are typically found in animal-waste enhanced muds, the oviposition preferences of gravid females for muds enhanced with different farm animal manures is unknown to date [27]. We hypothesized that WTD manure acts as a strong oviposition attractant/ stimulant for C. stellifer. However, our results indicate that white-tailed deer manure does not have a major impact on midge oviposition. This is evident from the whitetailed deer manure $v s$ DI control experiments as well as from mud + white-tailed deer manure $v s$ mud control trials, where the proportion of eggs deposited on whitetailed deer manure substrates was not much different to those deposited on controls. Our findings demonstrate that WTD manure does not play a significant role in the oviposition of C. stellifer and suggest that the field sites receiving manure influx from WTD particularly in commercial cervid farms may not be relatively more attractive for C. stellifer oviposition over muds without WTD manure. This suggests that manure management, which has been proposed as one of the cultural management strategies for filth fly control [66-68] and to some extent for C. sonorensis control [20] on livestock operations, may not be an effective strategy to reduce C. stellifer populations in/ around cervid facilities. However, it is important to note that the site from which sympatric mud samples were collected for this study had a variety of cervid as well as bovid species free ranging across the property with the animals frequently visiting this site. It is currently uncertain whether or to what extent influx of manure residue from other cervids or bovids occurred into the mud that could have potentially influenced midge choices in this study. Moreover, if olfactory cues from animal manure play a bigger role in midge oviposition than contact cues, it may cause potential errors in the recognition of the cue source by midges as the substrates in this study were placed in relatively small sized paper cups. Interestingly, the total proportion of egg batch (treatment + control) deposited by midges during the experiments involving WTD manure was very high ( $\geq 96.2 \%$; Fig. $2 a, b)$ compared to most of other experiments, which possibly suggests a positive impact of manure odors on oviposition. Therefore, further studies using, for example wind-tunnel Y-choice olfactometers that prevent physical contact of midges with the substrate, may provide a better assessment of the role of animal manure on midge oviposition. Previous studies on certain dung breeding Culicoides species [46], house flies [45] and stable flies [44] suggested that some animal manures are more attractive for oviposition than others. Furthermore, age of manure was shown to influence insect oviposition as some insects prefer fresh manure while some others prefer aged manure [69] (but only fresh WTD manure [ $<6 \mathrm{~h}$ old] was used in this study). Moreover, diet of the animals can also change the attractiveness of resulting manure for insect oviposition [70]. Therefore, 
these findings should be interpreted cautiously as the role of any of these factors on the oviposition of $C$. stellifer or other related species is unknown and further studies will be needed to examine whether the findings of this study are biologically significant.

Vegetation (Sphagnum spp. mosses) from the larval habitat appears to be a key factor in influencing the oviposition of C. stellifer. This is evident from the moss $v s$ DI control trials where a distinctly higher mean number/proportion of eggs were deposited on moss substrates over DI controls (Fig. 2a, b). Another result that stands out in this experiment is that the proportion of egg batch deposited by females was the highest (100\%) among all experiments, indicating a strong positive impact of the moss on midge oviposition (Fig. 2a). The effect that moss has on midge behavior/physiology that encourages the females to deposit $100 \%$ of their egg batch compared to the other natural sources examined is currently unknown and remains to be investigated in future studies. Previously, Sphagnum spp. moss and other vegetation (Juncus spp.) were shown to elicit a strong oviposition response in Culicoides impunctatus Goetghebuer, the Scottish biting midge, under laboratory conditions [26], supporting our own findings. Moreover, C. impunctatus larval densities in the field were found to be significantly correlated to the distribution of Sphagnum spp. and Juncus spp. along with a variety of abiotic factors [71, 72]. Interestingly, certain members of the piliferus group in North America, such as Culicoides bickleyi Wirth \& Hubert and Culicoides piliferus Root \& Hoffman, were previously reared from Sphagnum spp. bogs $[73,74]$, while larvae of numerous other midge species were found in habitats that had Osmunda fern bogs or other grasses [16]. Similarly, the distribution of some salt marsh Culicoides species was closely associated with vegetation such as Spartina alterniflora Loiseleur or Distichlis spicata (L.) Greene in North Carolina, USA [75]. Moreover, vegetated water bodies have been often found to harbor larvae of $C$. insignis (a confirmed vector of BTV in the United States) in cattle pastures and other areas [16, 76, 77]. Currently, the role of Sphagnum spp. moss and/or other vegetation on the oviposition and ecology of C. stellifer and other North American Culicoides species in nature is unknown. Whether vegetation has significant roles on the overall reproductive behavior such as swarming, mating, oviposition site selection, oviposition and/or even larval development of biting midges warrants further study. Indeed, a variety of plants have been observed to be used as swarm markers in certain Culicoides species [78]. A better understanding of the role of vegetation on the behavior and other life history traits of Culicoides species may provide novel insights into the spatial ecology of target midge species and provide clues towards their management by potentially targeting vegetation, particularly in/around livestock facilities. For example, the presence of vegetation and/or floating debris along the shoreline of animal waste lagoons has been shown to increase oviposition of Culex quinquefasciatus Say mosquitoes, and removal of this organic matter almost completely eliminated mosquito production from these otherwise productive habitats [79].

Field water, sampled from the larval habitat, appears to not have a major impact on the oviposition of C. stellifer. This is evident from the field water vs DI control trials where although a high proportion of eggs were deposited on substrates with field water than on DI controls, midge preference for the treatment substrate (field water) over controls (odds ratio) was not significant. This outcome is surprising because the immature stages of ceratopogonids are essentially semi-aquatic and soluble cues in the larval environment are likely present in the open standing water that is in contact with larval development sites. It is possible, however, that our results/ interpretations from the field water $v s$ DI control experiment is an artifact of the low gravid levels [mean number of eggs deposited $5 \pm 1$ (SE)] and low proportion of females that oviposited (only $2 / 9$ gravid females deposited eggs) during these trials compared to those during other experiments (Fig. 2a, b, Table 1, Additional file 1: Table S2). Therefore, these results should be interpreted cautiously. Nonetheless, breeding site water was also found to not stimulate oviposition in C. impunctatus under no-choice conditions previously [26], generally agreeing with our findings on $C$. stellifer.

The huge variation in oviposition rates among fieldcollected females in this study was not unexpected. It is possible that variation in the gravid levels, proportion of gravid females (out of total females collected), and females that successfully deposited eggs represents differences in blood meal volumes ingested by midges (partially blood-fed and fully-engorged females were not discriminated in this study) as size of the blood meal can influence insect fecundity [80,81], or a natural variation in the mated status or age of the fieldcollected females (older females may have had higher mortality before ovipositing than younger ones). However, variation in the proportion of egg batch deposited by females that did oviposit likely represents a differential likeability of the various substrates for midge oviposition, which can potentially be exploited in future colonization studies of C. stellifer (particularly Sphagnum spp. moss). Moreover, source of the blood meal can influence insect fecundity [82-84]. Therefore, future studies may also benefit by examining whether a mammalian blood meal (as opposed to avian blood meal used in this study) would cause fecundity variation in C. stellifer and other important midge species. 
Skip oviposition has been observed in several container-breeding mosquito species where the gravid female distributes its eggs over multiple sites, most likely to reduce larval competition in the resource limited container habitats that could be detrimental to larval survival [85-89]. Although such behavior in Culicoides species has never been documented before, our study demonstrates that a minor proportion of C. stellifer females do exhibit skip oviposition behavior, as evident from $9 \%(4 / 44)$ of females ovipositing on the two available dishes across the study (Fig. 3). However, in three of these cases, the females deposited most of their egg batch ( $\sim 90 \%$ on average) on one dish and a minor proportion on the second, while one female deposited an almost equal proportion of eggs on both dishes. Although skip oviposition may be advantageous in reducing larval densities in resource limiting habitats such as artificial containers, plant pitchers, or tree holes, the significance of skip oviposition on the life history traits of mud breeding species such as C. stellifer is currently unknown. Further studies will be needed to examine the role of skip oviposition on C. stellifer ecology, and whether skip oviposition occurs or is more prevalent in tree-hole breeders such as C. debilipalpis [16] and in other Culicoides species in general.

Insects may use a variety of physical and/or chemical cues that act as attractants or stimulants (or deterrents/ repellents) for selecting a suitable oviposition site. Some of the physical cues can be color, optical density, reflectance, texture or temperature [31,32], while chemical cues can originate from conspecifics, competitors, predators, decomposing organic material, vegetation or microbes [28-30, 55, 90, 91]. Our study suggests a strong role of olfactory and/or tactile cue components on the oviposition site selection of C. stellifer. Moreover, visual cues (color) may have also played a role, as the cotton/ filter paper placed on the treatment substrates were often discolored through time. Previously, visual cues were also suggested to play a role in the oviposition of certain Culicoides species [24, 26]. However, many of the other types of cues potentially utilized by biting midges for oviposition site selection are currently unknown and remain to be identified in further studies.

\section{Conclusions}

Mud and vegetation (Sphagnum spp. mosses) from the larval habitat likely provide stronger oviposition cues (olfactory/tactile/visual) to C. stellifer than field water or host animal (WTD) manure. Pollution of the mud habitat with WTD manure may not be a critical factor in the oviposition site selection of $C$. stellifer. Thus, management strategies to discourage oviposition of C. stellifer midges in/ around commercial cervid facilities should likely focus on mud and/or vegetation, rather than WTD manure.
Further studies will be needed to identify the key biotic/ abiotic factors in the larval habitat mud that influence oviposition site selection in C. stellifer and other important species. Moreover, further studies will also be needed to examine whether the spatial distributions of $C$. stellifer and Sphagnum spp. moss are correlated, and to determine whether targeting Sphagnum spp. moss and/or other types of vegetation in/around cervid facilities can contribute to reductions in local midge densities.

\section{Additional file}

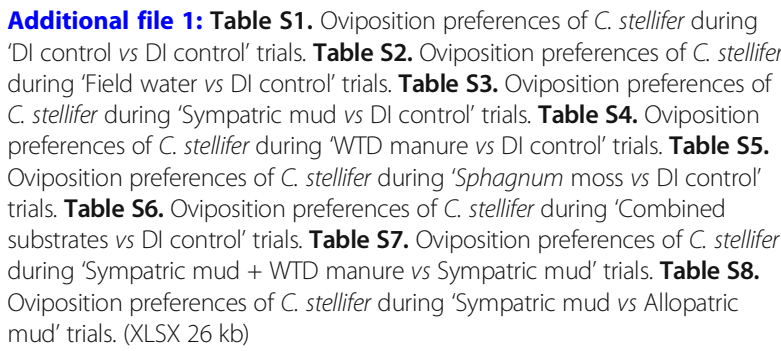

\section{Abbreviations}

BTV: Bluetongue virus; Cl: Confidence interval; DI: Deionized water; EHDV: Epizootic hemorrhagic disease virus; L:D: Light:dark; RH: Relative humidity; WTD: White-tailed deer

\section{Acknowledgements}

We thank Alfred Runkel, Bethany McGregor, Kristin Sloyer and Erik Blosser for assistance with the collection and/or maintenance of live midges. Agustin Quaglia conducted statistical analyses of the data. We also thank the commercial deer farmers in Quincy and Okeechobee (FL, USA), and MacArthur Agro-ecology Research Center, Lake Placid, FL, USA for allowing us to collect midges, manure and larval habitat samples from their properties.

\section{Funding}

This study was funded by the Cervidae Health Research Initiative (CHeRI) sponsored by the State of Florida legislature.

\section{Availability of data and materials}

All data generated or analyzed during this study are included in this article and its Additional file 1.

\section{Authors' contributions}

DE designed the study, conducted the experiments, and wrote the manuscript. NBC contributed to the study design. Both authors read and approved the final manuscript.

\section{Ethics approval}

Use of live chicken in this study was approved by the University of Florida Institutional Animal Care and Use Committee (IACUC) (Protocol \#7682). No human participants or human tissues were involved in this study.

\section{Competing interests}

The authors declare that they have no competing interests.

\section{Publisher's Note}

Springer Nature remains neutral with regard to jurisdictional claims in published maps and institutional affiliations. 


\section{Received: 2 February 2018 Accepted: 8 May 2018}

\section{Published online: 16 May 2018}

\section{References}

1. Carpenter S, Mellor PS, Torr SJ. Control techniques for Culicoides biting midges and their application in the UK and northwestern Palaearctic. Med Vet Entomol. 2008;22:175-87.

2. Pfannenstiel RS, Mullens BA, Ruder MG, Zurek L, Cohnstaedt LW, Nayduch D. Management of North American Culicoides biting midges: Current knowledge and research needs. Vector Borne Zoonotic Dis. 2015;15:374-84.

3. Tabachnick WJ. Culicoides variipennis and bluetongue-virus epidemiology in the United States. Annu Rev Entomol. 1996;41:23-43.

4. Mullen GR. Biting midges (Ceratopogonidae). In: Mullen GR, Durden LA, editors. Medical and Veterinary Entomology. 2nd ed. Burlington: Academic Press; 2009. p. 169-88.

5. Foster NM, Breckon RD, Luedke AJ, Jones RH. Transmission of two strains of epizootic hemorrhagic disease virus in deer by Culicoides variipennis. J Wildl Dis. 1977;13:9-16.

6. Jones RH, Roughton RD, Foster NM, Bando BM. Culicoides, the vector of epizootic hemorrhagic disease in white-tailed deer in Kentucky in 1971. J Wildl Dis. 1977;13:2-8.

7. Tanya VN, Greiner EC, Gibbs EP. Evaluation of Culicoides insignis (Diptera: Ceratopogonidae) as a vector of bluetongue virus. Vet Microbiol. 1992;32:1-14.

8. Smith KE, Stallknecht DE. Culicoides (Diptera: Ceratopogonidae) collected during epizootics of hemorrhagic disease among captive white-tailed deer. J Med Entomol. 1996:33:507-10.

9. Smith KE, Stallknecht DE, Sewell CT, Rollor EA, Mullen GR, Anderson RR. Monitoring of Culicoides spp. at a site enzootic for hemorrhagic disease in white-tailed deer in Georgia, USA. J Wildl Dis. 1996:32:627-42.

10. Vigil SL, Wlodkowski JC, Parris J, Edwards de Vargas S, Shaw D, Cleveland C, et al. New records of biting midges of the genus Culicoides Latreille from the southeastern United States (Diptera: Ceratopogonidae). Insecta Mundi. 2014:0394:1-14

11. Jewiss-Gaines A, Barelli L, Hunter FF. First records of Culicoides sonorensis (Diptera: Ceratopogonidae), a known vector of bluetongue virus, in southern Ontario. J Med Entomol. 2017;54:757-62.

12. Mullen GR, Hayes ME, Nusbaum KE. Potential vectors of bluetonque and epizootic hemorrhagic disease viruses of cattle and white-tailed deer in Alabama. Prog Clin Biol Res. 1985;178:201-6.

13. Mullen $G R$, Jones $R H$, Braverman $Y$, Nusbaum KE. Laboratory infections of Culicoides debilipalpis and C. stellifer (Diptera: Ceratopogonidae) with bluetongue virus. Prog Clin Biol Res. 1985;178:239-43.

14. Smith KE, Stallknecht DE, Nettles VF. Experimental infection of Culicoides lahillei (Diptera: Ceratopogonidae) with epizootic hemorrhagic disease virus serotype 2 (Orbivirus: Reoviridae). J Med Entomol. 1996;33:117-22.

15. Ruder MG, Lysyk TJ, Stallknecht DE, Foil LD, Johnson DJ, Chase CC, et al. Transmission and epidemiology of bluetongue and epizootic hemorrhagic disease in North America: current perspectives, research gaps, and future directions. Vector Borne Zoonotic Dis. 2015;15:348-63.

16. Blanton FS, Wirth WW. The sand flies (Culicoides) of Florida (Diptera: Ceratopogonidae). Arthropods Fla Neighb Land Areas. 1979;10:1-204.

17. Mullens BA, Rodriguez JL. Effect of experimental habitat shading on the distribution of Culicoides variipennis (Diptera: Ceratopogonidae) larvae. Environ Entomol. 1985;14:749-54.

18. Mullens BA, Rodriguez JL. Colonization and response of Culicoides variipennis (Diptera: Ceratopogonidae) to pollution levels in experimental dairy wastewater ponds. J Med Entomol. 1988;25:441-51.

19. Mullens BA, Rodriguez JL. Response of Culicoides variipennis (Diptera: (eratopogonidae) to water level fluctuations in experimental dairy wastewater ponds. J Med Entomol. 1989;26:566-72.

20. Mullens BA, Rodriguez JL. Cultural management of bluetongue virus vectors. Calif Agric. 1990;44:30-2.

21. Mullens BA, Rodriguez JL. Survival and vertical distribution of larvae of Culicoides variipennis (Diptera: Ceratopogonidae) in drying mud habitats. J Med Entomol. 1992;29:745-9

22. Pfannenstiel RS, Ruder MG. Colonization of bison (Bison bison) wallows in a tallgrass prairie by Culicoides spp. (Diptera: Ceratopogonidae). J Vector Ecol. 2015:40:187-90.

23. Erram D, Zurek L. Larval development of Culicoides sonorensis (Diptera: (eratopogonidae) in mud supplemented with manure of various farm animals. J Med Entomol. 2018:55:43-50.
24. Campbell MM, Kettle DS. Number of adult Culicoides brevitarsis Kieffer (Diptera: Ceratopogonidae) emerging from bovine dung exposed under different conditions in the field. Aust J Zool. 1976;24:75-85.

25. Linley JR. The effect of salinity on oviposition and egg hatching in Culicoides variipennis sonorensis (Diptera: Ceratopogonidae). J Am Mosq Control Assoc. 1986;2:79-82.

26. Carpenter S, Mordue (Luntz) AJ, Mordue W. Oviposition in Culicoides impunctatus under laboratory conditions. Entomol Exp Appl. 2001;101: 123-129.

27. Erram D. Characterization of the larval habitat of Culicoides sonorensis (Diptera: Ceratopogonidae) with emphasis on the significance of animal manure and the associated bacterial community. Ph.D. Dissertation: Kansas State University, USA; 2016. http://krex.k-state.edu/dspace/handle/2097/ 32573 Accessed 4 May 2016

28. Bentley MD, Day JF. Chemical ecology and behavioral aspects of mosquito oviposition. Annu Rev Entomol. 1989;34:401-21.

29. Leroy PD, Sabri A, Verheggen FJ, Francis F, Thonart P, Haubruge E. The semiochemically mediated interactions between bacteria and insects. Chemoecology. 2011;21:113-22.

30. Davis TS, Crippen TL, Hofstetter RW, Tomberlin JK. Microbial volatile emissions as insect semiochemicals. J Chem Ecol. 2013;39:840-59.

31. Allan SA, Day JF, Edman JD. Visual ecology of biting flies. Annu Rev Entomol. 1987;32:297-314

32. Clements AN. The physiology of mosquitoes. International series of monographs on pure and applied biology, Vol. 17. New York: Macmillan Co.; 1963.

33. Reiter P. Oviposition, dispersal, and survival in Aedes aegypti: implications for the efficacy of control strategies. Vector Borne Zoonotic Dis. 2007;7:261-73.

34. Day JF. Mosquito oviposition behavior and vector control. Insects. 2016;7:65.

35. Work TM, Sawyer MM, Jessup DA, Washino RK, Osburn BI. Effects of anesthetization and storage temperature on bluetongue virus recovery from Culicoides variipennis (Diptera: Ceratopogonidae) and sheep blood. J Med Entomol. 1990;27:331-3.

36. Okal MN, Lindh JM, Torr SJ, Masinde E, Orindi B, Lindsay SW, et al. Analysing the oviposition behaviour of malaria mosquitoes: design considerations for improving two-choice egg count experiments. Malar J. 2015;14:250.

37. Zuur AF, Leno EN, Walker NJ, Saveliev AA, Smith GM. Mixed effects models and extensions in ecology with R. New York: Springer Science and Business Media; 2009.

38. R Development Core Team. R: A language and environment for statistical computing. Vienna, Austria: R Foundation for Statistical Computing; 2014. http://www.R-project.org/

39. Venables WN, Ripley BD. Modern applied statistics with S. 4th ed. New York: Springer, Verlag; 2002

40. Fox J, Weisberg $S$. An $\{R\}$ companion to applied regression. 2nd ed. CA: Thousand Oaks; 2011. http://socserv.socsci.mcmaster.ca/jfox/Books/ Companion

41. Halekoh U, Højsgaard S, Yan J. The R package geepack for generalized estimating equations. J Stat Softw. 2006:15:1-11.

42. SAS Institute. Base SAS ${ }^{\oplus} 9.4$ procedures guide: statistical procedures. NC: SAS Institute Inc Cary; 2014.

43. Wasserberg G, Rowton ED. Sub-additive effect of conspecific eggs and frass on oviposition rate of Lutzomyia longipalpis and Phlebotomus papatasi. J Vector Ecol. 2011;36:S138-43.

44. Jeanbourquin P, Guerin PM. Chemostimuli implicated in selection of oviposition substrates by the stable fly Stomoxys calcitrans. Med Vet Entomol. 2007:21:209-16.

45. Shah RM, Azhar F, Shad SA, Walker WB, Azeem M, Binyameen M. Effects of different animal manures on attraction and reproductive behaviors of common house fly, Musca domestica L. Parasitol Res. 2016;115:3585-98.

46. Thompson GM, Jess S, Murchie AK. Differential emergence of Culicoides (Diptera: Ceratopogonidae) from on-farm breeding substrates in Northern Ireland. Parasitology. 2013;140:699-708

47. Schmidtmann ET, Bobian RJ, Belden RP. Soil chemistries define aquatic habitats with immature populations of the Culicoides variipennis complex (Diptera: Ceratopogonidae). J Med Entomol. 2000;37:58-64.

48. Schmidtmann ET. Testing the relationship between dissolved salts in aquatic habitats and immature populations of the Culicoides variipennis complex (Diptera: Ceratopogonidae). Environ Entomol. 2006;35:1154-60.

49. Schmidtmann ET, Herrero MV, Green AL, Dargatz DA, Rodriquez JM, Walton TE. Distribution of Culicoides sonorensis (Diptera: Ceratopogonidae) in 
Nebraska, South Dakota, and North Dakota: clarifying the epidemiology of bluetongue disease in the northern great plains region of the United States J Med Entomol. 2011;48:634-43.

50. Peterkova-Koci K, Robles-Murguia M, Ramalho-Ortigao M, Zurek L. Significance of bacteria in oviposition and larval development of the sand fly Lutzomyia longipalpis. Parasit Vectors. 2012;5:145.

51. Trexler JD, Apperson CS, Zurek L, Gemeno C, Schal C, Kaufman M, et al. Role of bacteria in mediating the oviposition responses of Aedes albopictus (Diptera: Culicidae). J Med Entomol. 2003;40:841-8.

52. Romero A, Broce A, Zurek L. Role of bacteria in the oviposition behaviour and larval development of stable flies. Med Vet Entomol. 2006;20:115-21.

53. Beehler JW, Millar JG, Mulla MS. Protein hydrolysates and associated bacterial contaminants as oviposition attractants for the mosquito Culex quinquefasciatus. Med Vet Entomol. 1994;8:381-5.

54. Maire A, Langis R. Oviposition responses of Aedes (Ochlerotatus) communis (Diptera: Culicidae) to larval holding water. J Med Entomol. 1985;22:111-2.

55. Allan SA, Kline DL. Larval rearing water and preexisting eggs influence oviposition by Aedes aegypti and Ae. albopictus (Diptera: Culicidae). J Med Entomol. 1998;35:943-7.

56. Elnaiem D-EA, Ward RD. Oviposition attractants and stimulants for the sandfly Lutzomyia longipalpis (Diptera: Psychodidae). J Med Entomol. 1992; 29:5-12.

57. Dougherty M, Hamilton G. Dodecanoic acid is the oviposition pheromone of Lutzomyia longipalpis. J Chem Ecol. 1997;23:2657-71.

58. Renwick JAA. Chemical ecology of oviposition in phytophagous insects. Cell Mol Life Sci. 1989;45:223-8.

59. Wondwosen B, Hill SR, Birgersson G, Seyoum E, Tekie H, Ignell R. A (maize) ing attraction: gravid Anopheles arabiensis are attracted and oviposit in response to maize pollen odours. Malar J. 2017;16:39.

60. Wondwosen B, Birgersson G, Seyoum E, Tekie H, Torto B, Fillinger U, et al. Rice volatiles lure gravid malaria mosquitoes, Anopheles arabiensis. Sci Rep. 2016;6:37930.

61. McCall PJ, Eaton G. Olfactory memory in the mosquito Culex quinquefasciatus. Med Vet Entomol. 2001;15:197-203.

62. McCall PJ, Kelly DW. Learning and memory in disease vectors. Trends Parasitol. 2002;18:429-33

63. Hamilton CE, Beresford DV, Sutcliffe JF. Effects of natal habitat odour, reinforced by adult experience, on choice of oviposition site in the mosquito Aedes aegypti. Med Vet Entomol. 2011;25:428-35.

64. Rejmánková E, Higashi R, Grieco J, Achee N, Roberts D. Volatile substances from larval habitats mediate species-specific oviposition in Anopheles mosquitoes. J Med Entomol. 2005;42:95-103.

65. Anderson DP, Frosch BJ, Outlaw JL. Economic impact of the United States cervid farming industry. Agricultural and Food Policy Center Research Report 07-4. Texas: Texas A\&M University, College Station; 2007.

66. Meyer JA, Shultz TA. Stable fly and house fly breeding sites on dairies. Calif Agric. 1990;44:28-9.

67. Fatchurochim S, Geden CJ, Axtell RC. Filth fly (Diptera) oviposition and larval development in poultry manure of various moisture levels. J Entomol Sci. 1989;24:224-31.

68. Axtell RC. Fly management in poultry production: cultural, biological, and chemical. Poult Sci. 1986;65:657-67.

69. Broce $A B$, Haas MS. Relation of cattle manure age to colonization by stable fly and house fly (Diptera: Muscidae). J Kans Entomol Soc. 1999;72:60-72.

70. Dougherty CT, Knapp FW. Oviposition and development of face flies in dung from cattle on herbage and supplemented herbage diets. Vet Parasitol. 1994;55:115-27.

71. Blackwell A, Lock KA, Marshall B, Boag B, Gordon SC. The spatial distribution of larvae of Culicoides impunctatus biting midges. Med Vet Entomol. 1999; 13:362-71.

72. Blackwell A, Young MR, Mordue W. The microhabitat of Culicoides impunctatus (Diptera: Ceratopogonidae) larvae in Scotland. Bull Entomol Res. 1994;84:295-301.

73. Wirth WW, Hubert AA. The species of Culicoides related to piliferus Root and Hoffman in eastern North America (Diptera, Ceratopogonidae). Ann Entomol Soc Am. 1962;55:182-95.

74. Jamnback H. The Culicoides of New York State (Diptera: Ceratopogonidae). N Y State Mus Sci Serv Bull. 1965;399:1-154.

75. Kline DL, Axtell RC. Distribution of Culicoides hollensis, C. furens and C. bermudensis in relation to plant cover in a North Carolina salt marsh (Diptera: Ceratopogonidae). J Med Entomol. 1977;13:545-52.
76. Kline DL, Greiner EC. Observations on larval habitats of suspected Culicoides vectors of bluetongue virus in Florida. Prog Clin Biol Res. 1985;178:221-7.

77. Kramer WL, Greiner EC, Gibbs EPJ. A survey of Culicoides midges (Diptera: Ceratopogonidae) associated with cattle operations in Florida. USA. J Med Entomol. 1985;22:153-62.

78. Blackwell A. Mordue (Luntz) AJ, Young MR, Mordue W. The swarming behaviour of the Scottish biting midge, Culicoides impunctatus (Diptera: Ceratopogonidae). Ecol Entomol. 1992;17:319-25.

79. Rutz DA, Axtell RC. Factors affecting production of the mosquito, Culex quinquefasciatus (= fatigans) from anaerobic animal waste lagoons. N C Agric Exp Stn Tech Bull. 1978;256:1-32.

80. Takken W, Klowden MJ, Chambers GM. Effect of body size on host seeking and blood meal utilization in Anopheles gambiae sensu stricto (Diptera: Culicidae): the disadvantage of being small. J Med Entomol. 1998;35:639-45.

81. Akoh Jl, Aigbodion Fl, Kumbak D. Studies on the effect of larval diet, adult body weight, size of blood-meal and age on the fecundity of Culex quinquefasciatus (Diptera: Culicidae). Int J Trop Insect Sci. 1992;13:177-81.

82. Richards SL, Anderson SL, Yost SA. Effects of blood meal source on the reproduction of Culex pipiens quinquefasciatus (Diptera: Culicidae). J Vector Ecol. 2012;37:1-7.

83. Downe AER, Archer JA. The effects of different blood-meal sources on digestion and egg production in Culex tarsalis Coq. (Diptera: Culicidae). J Med Entomol. 1975;12:431-7.

84. Bennett GF. The influence of the blood meal type on the fecundity of Aedes (Stegomyia) aegypti L. (Diptera: Culicidae). Can J Zool. 1970;48:539-43.

85. Mogi M, Mokry J. Distribution of Wyeomyia smithii (Diptera, Culicidae) eggs in pitcher plants in Newfoundland. Canada. Trop Med. 1980;22:1-12.

86. Davis TJ, Kaufman PE, Hogsette JA, Kline DL. The effects of larval habitat quality on Aedes albopictus skip oviposition. J Am Mosq Control Assoc. 2015 31:321-8.

87. Service MW. Population dynamics and mortalities of mosquito preadults. In: Lounibos LP, Rey JR, Frank JH, editors. Ecology of mosquitoes: Proceedings of a workshop. Vero Beach, FL: Florida Medical Entomology Laboratory; 1985. p. 185-201.

88. Mori A. Effects of larval density and nutrition on some attributes of immature and adult Aedes albopictus. Trop Med. 1979;21:85-103.

89. Corbet PS, Chadee DD. An improved method for detecting substrate preferences shown by mosquitoes that exhibit 'skip oviposition'. Physiol Entomol. 1993;18:114-8.

90. Hazard El, Mayer MS, Savage KE. Attraction and oviposition stimulation of gravid female mosquitoes by bacteria isolated from hay infusions. Mosq News. 1967;27:133-6.

91. Blaustein L, Kiflawi M, Eitam A, Mangel M, Cohen JE. Oviposition habitat selection in response to risk of predation in temporary pools: mode of detection and consistency across experimental venue. Oecologia. 2004;138:300-5.

\section{Ready to submit your research? Choose BMC and benefit from:}

- fast, convenient online submission

- thorough peer review by experienced researchers in your field

- rapid publication on acceptance

- support for research data, including large and complex data types

- gold Open Access which fosters wider collaboration and increased citations

- maximum visibility for your research: over $100 \mathrm{M}$ website views per year

At BMC, research is always in progress.

Learn more biomedcentral.com/submissions 